\title{
Envolvimento Pulmonar no Síndrome de Sjögren
}

\author{
Pulmonary involvement in Sjögren's Syndrome
}

\section{Moura S, Pereira C}

Serviço de Medicina Interna Unidade Local de Saúde do Nordeste

Os autores apresentam o caso clínico de uma doente do sexo feminino, 54 anos, com história de dispneia e tosse seca com 4 anos de evolução e síndrome sicca. Ao exame objetivo observou-se hipocratismo digital. Do estudo realizado: análises com velocidade de sedimentação aumentada; gasometria arterial com insuficiência respiratória hipoxémica, provas de função respiratória com alteração obstrutiva moderada e défice grave de DLCO (capacidade de difusão pulmonar do monóxido de carbono). A TAC (tomografia axial computorizada) torácica mostrou padrão de mosaico bilateral (figuras 1 e 2). No decurso do estudo efetuou broncofibroscopia com lavado broncoalveolar sugestivo de alveolite linfocítica com predomínio de linfócitos T CD4. 0 estudo imunológico revelou anticorpos ANA (antinucleares), SSA/SSB (Ro/La) positivos em alto título. 0 restante estudo permitiu o diagnóstico definitivo de Síndrome de Sjögren primário. Iniciou tratamento com prednisolona $1 \mathrm{mg} / \mathrm{Kg} / \mathrm{dia}$.

As manifestações pulmonares no Síndrome de Sjögren são comuns, podem ocorrer isolamente ou concomitantemente. No caso apresentado verificou-se atingimento das pequenas vias aéreas traduzido pelo padrão em mosaico e pneumonia intersticial ${ }^{1,2}$.

\section{Bibliografia}

1. Stojan, G., Baer, A. N., \& Danoff, S. K. (2013). Pulmonary manifestations of Sjögren's syndrome. Curr Allergy Asthma Rep., 13(4), 354-360.

2. Egashira, R., Kondo, T., Hirai, T., Kamochi, N., Yakushiji, M., Yamasaki, F., \& Irie, H. (2013). CT findings of thoracic manifestations of primary Sjögren syndrome: radiologic-pathologic correlation. Radiographics. 33 (7), 19331949.
Figura 1. TAC torácico com alta resolução com visualização difusa de áreas hiperlucentes ao lado de outras de normal densidade, conferindo a ambos os pulmões um padrão em mosaico, decorrente de compromisso das pequenas vias aéreas.

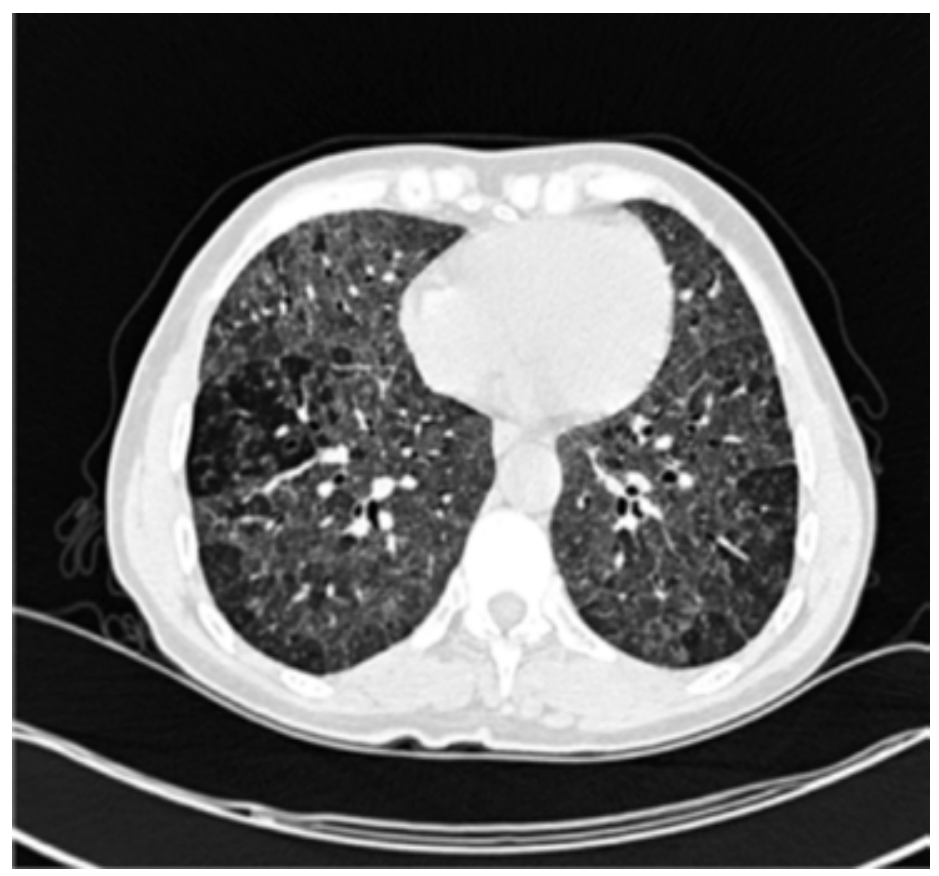

Figura 2. Imagem coronal de TAC torácico com alta resolução mostrando padrão em mosaico mais notário nas pirâmides basais.

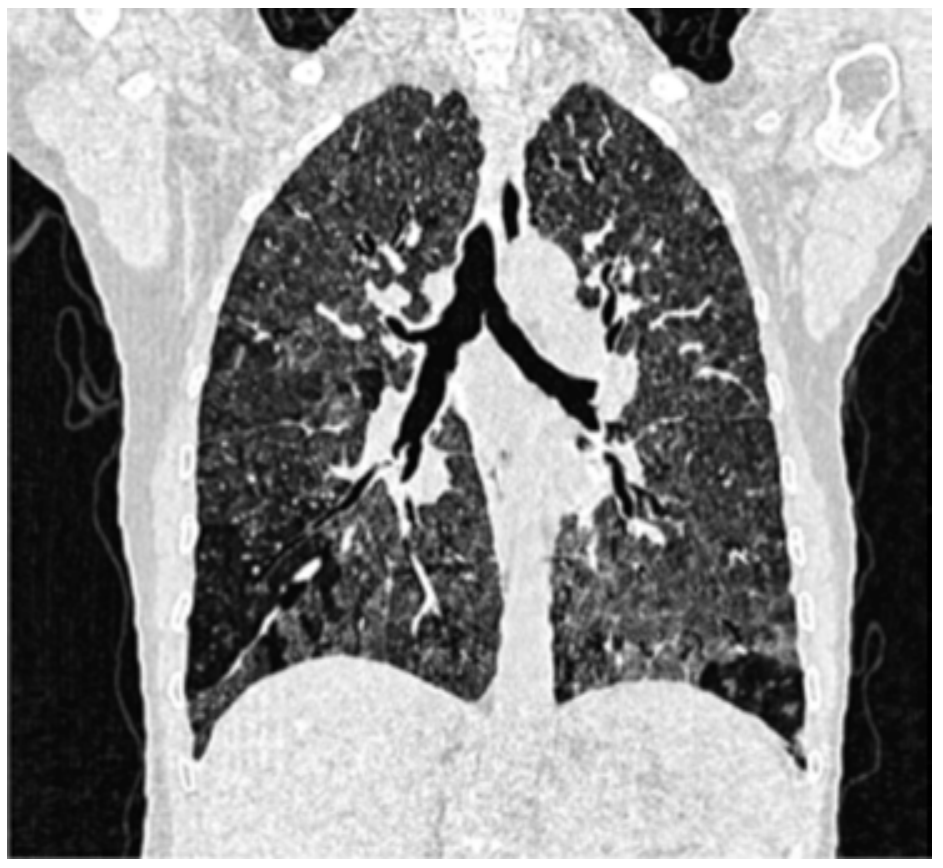

